\title{
De la Iași la Paris sau calea către sine a lui Benjamin Fondane
}

De Iaşi à Paris ou le chemin vers soi-même de Benjamin Fondane

\section{Speranța Milancovici}

\section{OpenEdition}

\section{Journals}

Édition électronique

URL : https://journals.openedition.org/cher/10155

DOI : $10.4000 /$ cher.10155

ISSN : 2803-5992

\section{Éditeur}

Presses universitaires de Strasbourg

\section{Édition imprimée}

Date de publication : 1 décembre 2013

Pagination : 67-76

ISBN : 978-2-86820-560-5

ISSN : 1968-035X

Référence électronique

Speranța Milancovici, «De la lași la Paris sau calea către sine a lui Benjamin Fondane », reCHERches [En ligne], 11 | 2013, mis en ligne le 08 février 2022, consulté le 09 février 2022. URL : http:// journals.openedition.org/cher/10155; DOI : https://doi.org/10.4000/cher.10155

\section{cc) (1) (ㅇ)}

Ce(tte) œuvre est mise à disposition selon les termes de la Licence Creative Commons Attribution Pas d'Utilisation Commerciale - Partage dans les Mêmes Conditions 4.0 International. 


\title{
De la lași la Paris sau calea către sine a lui Benjamin Fondane \\ De laşi à Paris ou le chemin vers soi-même de Benjamin Fondane
}

\author{
Speranța Milancovicl \\ Université de Arad - Roumanie
}

\begin{abstract}
Doet, critic literar, traducător, eseist, filosof și cineast, ambasador al filmului francez în America Latină, Benjamin Fundoianu s-a născut la Iași, în 14 noiembrie 1898 (notăm o interesantă incertitudine privind data nașterii sale, pe care el însuși o semnalează, în Pagini dintr-un confesional: pe documentele oficiale, se pare că a fost consemnată data de 15 noiembrie). Începuturile călătoriei lui existențiale stau, așadar, chiar de la naștere, sub semnul unei rătăciri care îi va deveni emblematică.
\end{abstract}

Numele său real este Benjamin Wechsler, fiul lui Isaac Wechsler şi al Adelei Schwartzfeld, intelectuali evrei care l-au numit, conform tradiției iudaice, după bunicul său matern, Benjamin Schwartzfeld, pedagog şi cercetător al istoriei evreilor, pionier al iluminismului iudaic în România și iniţiator al primei şcoli pentru copiii evrei de la Iaşi.

Copilăria lui Benjamin Fundoianu este indisolubil asociată Herței, localitate situată nu foarte departe de Iași, actualmente cuprinsă însă în teritoriul ucrainian. Așezare cu o cultură preponderent evreiască, acest colț moldav se regăsește frecvent, decantat liric, în substanța poeziilor în limba română, dar și în cele ale etapei franceze ulterioare. Un întreg ciclu al Priveliștilor poartă titlul Herța, colț de lume unde "în case oameni simpli vorbesc pe ovreieşte", "Seara, un murmur negru creştea din sinagogi" iar bunicul, mare patriarh al familiei, "între flăcări de sfeşnic se ruga..." (Fundoianu 1965: 7-15). 
Într-un fragment de manuscris până la ora actuală inedit (fondul Bibliotecii Doucet, Paris), Iașiul este descris drept un oraș prăfuit, obosit și totuși cadru al formării sale culturale, precum și al contactului prim cu poezia:

Oraşul meu, fostă capitală a Moldovei, de câte ori îmi surâzi enigmatic, cu ochii morți și trupul prăpădit, prin geamurile spălate de ploaie, îmi faci impresia unei fantome neînsuflețite, unui cadavru ambulant din poveștile chineze. Îmi faci impresia unei bunici bătrâne și ofilite cu crețuri rigide în obraji, cu bunătate molcomă, cu mers greoi, cu dragoste statornică și dulce... Și totuși în tine am făcut cei dintâi pași din viață, în tine am urmat instituțiile de cultural supliciu, în tine am gustat emoția intensă a poeziei [...]

Istoria Iaşiului e istoria unui om fără de noroc. $\mathrm{O}$ istorie lentă, tristă, bolnăvicioasă. Un prieten îmi spunea odată că ori de câte ori vorbește de orașul acesta, binecuvântat de Dumnezeu, capătă guturai, numai vorbind.

Imaginea bunicilor paterni se integrează organic în tabloul Herței, evocând simbolul rădăcinilor, legătura identitară și culturală determinată pentru paradigma în care se va înscrie ulterior Benjamin Fundoianu, dezrădăcinatatul, obsedat de rădăcini, evreu adevărat, de o deosebită fecunditate spirituală. Iată Herța, așa cum apare filtrată într-un text manuscris, inedit în cea mai mare parte și conservat în fondurile Bibliotecii Doucet din Paris:

Eu mă gândesc la Herța; văd parcă iar vacanțiile lungi și leneșe, simt parcă din nou aerul ce se tescuia din păduri și parcă mă văd din nou, ca odinioară, pe drumul către Herța. [...]

Mă duceam să îmi văd bunicii. Inima îmi bătea ca un clopot, ochii îmi erau umezi, îi vedeam parcă pe amândoi în prag, alungând cu mătura o căpriță sprințară, ce căuta să fărâme frunzele de nalbă. Îi vedeam în prag și eram cuprins de o neînchipuită veselie. Căci e o mare plăcere ca să-ți vezi bunicii! [...]

Când intri în târg, diligența contenește trapul și caii sleiți de-atâtea coclauri îşi pleacă capetele ostenite de drum. Luminile sunt aprinse pretutindeni. Când diligența intră în târg, ovreii toți răsar în prag. La ferestre, femeile apar cu țâncii rebegiți subt greutatea mameloanelor suculente. Copiii se iau după trăsură şi-i zarvă și-i zgomot... Apoi trăsura mă ducea la căsuța mică în care bunicii mă așteptau în prag...

Bunicul matern e doar o efigie, care însă a amprentat irevocabil devenirea culturală a nepotului. Biblioteca acestuia, descoperită de nepot în podul casei, reprezintă un colț de paradis terestru, un spațiu sacru unde tânărul 
pornește un parcurs inițiatic. O mărturie proprie din paginile "Sburătorului Literar" - 1921, redă întâlnirea spirituală cu bunicul, mediată de bibliotecă:

De câte ori, în fața bibliotecii bunicului, pe care am moştenit-o ca s-o continui, $\mathrm{m}$-am oprit la volumele cu buche de aur pe spinare, rămase tefere în raft, deşi ediția lor a fost cândva afurisită şi arsă de sinagogă! Câtă dragoste trebuie să fi avut pentru artă omul care a cumpărat, din meschina lui avere de zaraf, cartea asta scumpă - ca să-şi poată ucide ochii pe dânsa, ca s-o poată aşeza în raftul lui, pentru bucuria interioară. Nu l-am cunoscut pe bunic, dar mâna lui m-a dezmierdat din fila atâtor cărți, sufletul lui mi-a surâs din atâtea slove de aur şi genunchii lui m-au legănat, de atâtea ori, de sub infoliile vechi, din care-mi culeg, cum îşi culegea şi el, nevoia unei lumi mai frumos trăite şi bucuria de a o găsi aşa de lesne... Cei care citesc, fără să păstreze cartea, cei care-o împrumută făă să simtă neliniştea şi tortura n-au câştigat, chiar când le e mare meritul, nici un sfert din noțiunea de cultură. (Fundoianu 1980: 142-143).

Un aspect determinant în ceea ce privește configurația multiculturală a spiritualității lui Benjamin Fundoianu/Fondane îl constituie matricea formativă, dictată de cadrul și contexul socio-politic al nașterii sale. Acolo și Atunci era locul și momentul marilor întâlniri culturale, ideologice și de mentalitate. Interesele imperiilor habsburgic, otoman și țarist se întâlnesc într-o zonă de confluență a religiilor, atitudinilor, mentalităților și felurilor de "a fi" în lume.

Este, aşadar, vorba despre un spațiu multicultural prin esență, un cadru care lasă o tușă distinctă unei personalități de o atât de acută sensibilitate și finețe receptivă cum s-a dovedit a fi cea a scriitorului în cauză. Iar orice referire la interculturalitate înseamnă, implicit, interacțiune, schimb, reciprocitate, solidaritate obiectivă. (Dasen, Perregaux, Rey 1999: 166)

Unul dintre materialele păstrate în arhiva lui Paul Daniel, "lada cu amintiri”, care a rămas după plecarea definitivă, din țară şi, mai apoi, din lume, a lui Bemjamin Fundoianu, poartă titlul Pagini dintr-un confesional, text "uitat" nepublicat. La momentul conceperii acestor eseuri, Benjamin Fundoianu avea 18 ani. Amprenta originilor se face simțită, evident, încă din copilărie. Problema identității apare încă de pe acum: incontestabil marcat de tradiția iudaismului, prin întreaga zestre familială, copilul Fundoianu (pe atunci Wechsler) prinde rădăcini în solul spiritual românesc, fertilizându-se prin lecturi din literature sau filosofia occidentală.

Manuscrisul are o valoare sporită de faptul că, nefiind destinat unui ochi străin, dezvăluie felii de suflet care, la rândul lor, lasă să se întrevadă geografia spirituală a scriitorului, așa cum se conturase ea la momentul respectiv. 
Tânărul Benjamin Fundoianu a urmat studiile primare și secundare "Trei Ierarhi”, la Iaşi, perioadă în care publică deja materiale în reviste ca "Vieața nouă" a lui Ovid Densuseanu, "Cronica", "Valuri" etc., sub diferite pseudonime: Ofir, Ha-Shir, Alex Vilara, Wechslerescu, Iaşanul, Dionmède, Dănoiu şi, finalmente, Benjamin Fundoianu. Acest pseudonim este derivat de la numele moşiei tatălui său, situată în apropiere: Fundoaia. Pseudonimul va fi, ulterior, ușor transformat, odată cu abordarea limbii franceze ca patrie lingvistică, în Fondane.

Ca student al Facultății de Drept din Iași, așa cum era de așteptat, Benjamin Fundoianu a avut de înfruntat manifestări antisemite inerente faptului că decanul științelor juridice ieșene era nimeni altul decât A. C. Cuza.

Abia în anul 1920, tânărul părăsește Iașiul pentru a se stabili în București. În această perioadă, paleta publicaţiilor care îi găzduiesc scrierile devine din ce în ce mai largă, iar talentul îi este deja recunoscut de către personalitățile culturale ale timpului, prestigiul său fiind în ascensiune.

În perioada bucureșteană, Benjamin Fundoianu a fost un fin cronicar teatral, plastic, literar, dar și un actor activ al avangardei, alături de Ion Vinea, Ilarie Voronca, Sașa Pană, Ștefan Roll, Marcel Iancu, M. H. Maxy, F. Brunea-Fox etc. De altfel, în 1922, la apariția fanionului direcțiilor noi, publicația "Contimporanul”, Benjamin Fundoianu semnează, încă din primul număr, un articol intitulat Spre Europa. Fireşte, cu renumita (deja) subtilitate care îl caracteriza, "viciul său evident" (Cioran 1988: 266), autorul militează pentru deschiderea spre valorile occidentale.

Anul 1923 marchează despărțirea oficială și definitivă a lui Benjamin Fundoianu de România, de patria literară, lingvistică aferentă și chiar de propriul nume. $\mathrm{Nu}$ e vorba despre un exil determinat de factori sociopolitici, ci de propria sa alegere, dictată probabil de atracția irezistibilă față de cultura formatoare a Franței. Aici se afla, în perioada zorilor secolului al xx-lea, epicentrul cultural și artistic al Europei, acolo se află, considerăm, și astăzi.

Astfel, nou-născutul Fondane pornește într-o călătorie nu doar geografică, ci mai ales spirituală, navigând în speranța identificării unor forme de expresie artistică și filosofică adecvate mesajului existențial pe care și 1-a asumat.

În lumea pariziană, Fondane se integrează natural și cu eleganță, bucurându-se foarte rapid de o reală apreciere, dovadă casele pe care le frecventează, grupurile în care se integrează sau revistele care îl publică. 
În martie 1925, la București, are loc un eveniment cultural remarcabil: F. Brunea-Fox și colaboratorii săi creează revista "Integral”. În acest context, dezmințindu-și declarațiile de radicală desprindere de provincialismul românesc, Benjamin Fundoianu, alături de Ilarie Voronca, își asumă spațiul redacțional destinat aspectelor culturale pariziene.

Începând din 1928, afirmarea sa în Franța devine deplină. Texte ale sale se regăsesc în paginile publicațiilor pariziene, volumele sale văd, frecvent, lumina tiparului, la prestigioase edituri. Primul său poem publicat în Franța poartă titlul Le regard de l'absent şi se regăseşte în paginile revistei "Discontinuité", a grupării cu acelaşi nume condusă de Arthur Adamov şi Claude Sernet.

În această perioadă, Fondane traduce şi prefaţează romanul fostului său mentor A. L. Zissu, Spovedania unui candelabru, dezvoltând şi preocupările pentru filosofie.

Scriitorul mânuieşte limba franceză cu o pricepere apropiată de perfecțiune, fapt remarcat şi de exegeții săi francezi, ceea ce îi permite încercări poetice în noua patrie lingvistică.

Anul 1940 este, și pentru Benjamin Fondane, unul nefast. Mobilizat la un regiment de infanterie aproape de Fontainebleau, cade prizonier, dar evadează. Este prins, apoi eliberat din motive de sănătate, fiind, ulterior, operat de ulcer și internat, o bucată de vreme, la Val-de-Grâce. Însă problemele de sănătate nu îl descurajează, nici nu îl împiedică să publice, în continuare, articole în Cahiers du Sud, Fontaine sau "Sur".

În data de 7 martie, 1944, Fondane este arestat de poliția franceză, împreună cu sora sa, Lina, dintr-o imprudență: avertizat, în repetate rânduri, să se ascundă, Fondane nu rezistă fără cărțile sale. Pentru a le recupera, comite tragica eroare de a se întoarce la locuința pariziană. Denunțat de un vecin colaboraționist, cade victimă nebuniei naziste. Internat, împreună cu sora sa, la Drancy, va fi, ulterior, deportat la Auschwitz, în 30 mai. Aici, traseul său de călător existențial se pierde în abis.

Firii lui Benjamin Fundoianu/Fondane îi pot fi asociați câțiva termeni. Dintre aceștia, notăm disimularea, "jocul" cu propria identitate, "jocul" cu destăinuirile spirituale.

Vizionarismul nu îl inspiră pe poet: "e o meserie care renta numai în antichitate" - notează el cinic. Totodată, el nu vede calea autodefinirii nici în renegarea originilor: "Dar nici antisemit, deşi e o meserie care rentează astăzi îngrozitor” (Fundoianu 1998: 125). 
Dacă nu îşi neagă rădăcinile evreiești, Fundoianu optează însă pentru o lepădare a locului, (dacă am numi zestrea ereditară - fondul) cu alte cuvinte a hainei de românism mascând o altă natură.

Reîncarnarea sa, urmare a uciderii sinelui de către sine, ne aduce în fața ochilor pe Benjamin Fondane, poet şi filosof francez, apărut în urma unei voite metamorfoze.

Dualismul este un alt termen-cheie într-o discuție despre structura spirituală fondaniană. Reflecțiile teoretice privind originile ascund o dramatică pendulare a spiritului pornit în căutarea propriei determinări, între două religii, între două etnii, între două feluri de a Fi în lume şi de a te raporta la aceasta.

Secvențele autobiografice restituite în manuscrise vin să lumineze conuri de umbră din complexitatea structurii spirituale pe care o lasă a se întrevedea textul.

Atitudinile identitare transcrise de text sunt asumarea, respingerea (chiar negarea) şi/sau disimularea. Fiecare dintre aceste raportări la propria origine reflectă trăiri organice care îşi găsesc exprimarea (textul) în spațiul concret (contextul) bulversat al anilor premergători celei de a doua conflagrații mondiale.

Reținerea, timbrul filosofic, menținut departe de zbaterile politico-sociale, de registrul concret, al vieții comunităţilor de evrei, este de asemenea un aspect care vizează problema raportării la identitate. Perspectiva culturală, atemporală şi desprinsă parcă de autor transcrie o stare interioară.

Această dublă sau chiar triplă identitate (iudaică - română - franceză) este trăită în mod organic, natural, firesc? Putem discuta despre o scindare, o dramă identitară sau o criză? Sau este vorba despre persoane diferite care locuiesc același corp, așa cum susține Benjamin Fondane care, odată integrat în universul cultural francez, proclamă moartea avatarului său român, în termenii unui act de deces?

Putem urmări ipostazele acestei identificări culturale, de la fidelitate la respingere, de la credință la renegare, de la elogiu la blasfemie. Dincolo însă de propriile consemnări cu privire la separarea radicală și definitivă de pseudocultura română, dincolo chiar de negarea ab initio a existenței acesteia, identificăm, în etapa franceză a creației sale poetice, ecouri ale cadrului formator românesc.

Într-o analiză dedicată Cuvintelor pădurețe, Mircea Marin remarcă just faptul că e mai mult decât evident că poetul "își mai iubește încă vechea poezie, 
de vreme ce o apără și... o publică, deși publicarea însăși o interpretează ca pe obiectivarea unei despărțiri”". (Martin 1984: 22). Extrapolând, considerăm la fel de evident faptul că Benjamin Fondane iubește încă, în etapa franceză de creație, literatura română, din moment ce o neagă dar o traduce, o acuză dar o promovează, o blamează dar o completează fericit.

Din substanța acestor atitudini transpare, pentru cercetătorul avizat, frustrarea celui care deslușește, în cultura care l-a format, potențialități nevalorificate și care încearcă să disimuleze regretul de a nu fi agreat şi acceptat, pe cât și-ar fi dorit, de conaționalii săi.

Într-un manuscris aflat în arhivele Academiei Române (Archives Felix Aderca, IV, MS 62 a-c), reprezentând corespondență personală între Felix Aderca și Benjamin Fondane, aceasta din urmă așterne pe hârtie opinii dure privind cultura română, indicând drept motiv al plecării sale faptul că aceasta nu există și, mai grav, convingerea că nu va exista niciodată.

Însă, în corespondența sa cu Liviu Rebreanu (arhivele Academiei Române, 54 (1-3) CMLXI), același Fondane, proaspăt întors din Argentina, ișsi pune relațiile intelectuale în slujba promovării culturii autohtone. E doar un exemplu din alternanța trăirilor lui Fondane prin raportare la spațiul cultural românesc, menit să justifice afirmația potrivit căreia scriitorul în discuție propune, drept soluție pentru revigorarea culturii române, exorcizarea de patina lâncedă a imobilității ideatice.

În etapa formării sale literare franceze, Benjamin Fondane reține şi transpune în versuri mireasma tare a fânului, amestecată cu sudoarea impregnată în trupul țăranului român, adus din Moldova copilăriei până în grandioasa lume a literelor franceze:

Les paysans viendront dans une odeur de foin,

$[\ldots]$

Paysans en chemise brodée... (Radiographies, I)

Imaginea recurentă a vidului constituie un alt aspect de continuitate la nivelul stilului, dar şi al mesajului, între operele celor doi scriitori, pe care ne-am obişnuit să îi detectăm într-unul singur.

Ulysse, erou mitic cu care poetul se identifică, ("Juif naturellement et cependant Ulysse" - Ulysse, à Ilarie Voronca) este simbolul unei existențe sub pecetea blestemului, a trăirii neresemnate cu speranța fericirii, care rămâne însă doar potențială. Eul liric se regăseşte mereu singur şi neiubit, ("voici la vérité je suis seul" - Ulysse, XVII) iar în această ipostază existențială, un reper îl constituie, iar şi iar, satul moldovean cu boi şi gâş̧e, cu ofticoşi 
şi case dărăpănate, cu suflete de noroi, dar curate. În cel de al XI-lea poem, intitulat Chanson de l'Emigrant, poetul face trimiteri la râul Olt, în cel de al vi-lea, amintește de câmpiile Basarabiei.

Ciclurile Radiografii şi Poetul şi umbra sa transcriu, iar şi iar, tragedia rătăcitorului, a evreului a cărui sensibilitate, istorie, condiție socială, viață şi moarte s-au aflat mereu sub zodia cumplitei şi zadarnicei peregrinări.

Original, vidul îşi pune amprenta până şi pe înfățişarea feminină: “...de vieilles filles patinées par le vide" (Radiographies, $I$ ).

Satul din Privelişti transpare din substanța versurilor franceze, ca o dominantă a spiritului, care nu l-a părăsit pe poetul lansat în aventura marii metropole culturale pariziene:

Je viens d'une petite ville blanche où pissaient les vaches les héliotropes débordaient le soutien-gorge des haies une odeur de soleil qui s'est lavé à l'eau des fourmis longuement marchaient sur les mains calmes une chèvre broutait du lait... (Ulysse, $V$ )

Sintagmele sunt similare cu cele care dau nota distinctivă poemelor din Privelişti, un bucolism al percepțiilor care însă este doar interfața unor trăiri profunde şi neliniştitoare. Soarele "s-a spălat - aici - cu apă", gest atribuit, în Privelişti, liniştii, iar dobitoacele sunt aceleaşi, tâmpe şi calme, îndeplinind un ritual cosmic prestabilit.

Lumina are, de asemenea, atribute pe care le cunoaştem din etapa românească: e sălbatică, rea, crudă, pătrunzătoare când face să doară şi incertă când ar trebui să fie penetrantă: "nous étions écrasés par cette lumière inhumaine" (Ulysse, $V$ ).

Identificăm așadar, la o privire de ansamblu asupra configurației poeziei lui Fundoianu / Fondane, o punte solidă care traversează universal său liric, resorturi care conectează satul imobil - marcă a ținutului natal moldovenesc - cu marile metropole ale volumelor franceze ulterioare.

Continuitatea unor teme care l-au preocupat în tinerețe, reluarea unor dileme, transpunerea satului tradițional, a țăranului român din zonele copilăriei, ba mai mult, chiar a faunei domestice moldoveneşti în versurile pariziene, anulează opinia simplistă potrivit căreia Fondane s-a debarasat de Fundoianu, avatarul român nefiind altceva decât o identitate tranzitorie, de care te poți lepăda precum de o haină pe care o lași în drum... De la singurătatea fizică a lui Robinson la cea metafizică a omului modern, poezia 
lui Fundoianu - Fondane este expresia literară continuă a luptei curajoase şi susținute a omului cu lumea.

Putem formula fără rețineri o certitudine: poezia lui Benjamin Fondane nu poate fi analizată de profundis fără poezia lui Benjamin Fundoianu. Sintagmele atât de specific fundoniene, transpuse în limba franceză, nu îşi pierd nici noutatea, nici ineditul, nici inconfundabila savoare.

Satul Priveliştilor e prezent în substanța lirică franceză, la fel cum e prezent țăranul român cu cămaşa lui brodată, sau vacile tâmpe şi domoale, mesagere ale unui suflu vital din străfundul firii.

Tot atât de cert e faptul că poetica lui Benjamin Fundoianu/Benjamin Fondane, cu multiplele sale fațete şi deschiderea extraordinară spre tot ceea ce înseamnă înnoire în planul creației, păstrează calea unui modernism în sensul echilibrat al termenului, fără derapări majore înspre curente extremiste sau spre o tradiție iremediabil depăşită. Însă fondul său marcat incontestabil de zbateri lăuntrice 1-a făcut mai receptiv în privința expresionismului şi a existenţialismului. Ceea ce nu l-a împiedicat să fie, aşa cum doar Benjamin Fundoianu / Benjamin Fondane ar fi putut, un om şi un poet, un eseist şi un filosof al diversității şi al deschiderii spre valoare, în fantastica varietate de orientări care s-au oferit artistului în anii de început ai secolului al xx-lea.

Născut în contextul nefast al nebuniei naziste, sub zodia Holocaustului, Fundoianu / Fondane a fost, dincolo de omul dezrădăcinat, dar, paradoxal, obsedat de rădăcini, evreu. Evreu adevărat, cu o individualitate inadaptabilă şi de o deosebită fecunditate spirituală.

Prin ansamblul textelor sale literare, a materialelor publicate în presa vremii şi a prolificei sale activităţi filosofice şi de cineast, Benjamin Fundoianu a fost purtătorul de stindard al avangardismului românesc peste hotare şi al înnoirilor, al sincronizărilor cu suflul contemporan, pe plan intern. A reuşit să se înscrie cu succes în marea cultură a Franței, dezmințind prin propriul exemplu temerile pe care le-a enunțat și care vizau statutul periferic, colonial, al culturii române. Traseul existențial pornind de pe meleaguri moldovene se încheie tragic dar glorios, prin succesul integrării organice în universul cultural francez, acolo unde talentul i-a fost pus la incercare prin proba de foc a confruntării cu standardele valorice occidentale. 


\section{Bibliographie}

Calimani R., 2002, Destins et aventures de l'intellectuel juif en France, 1650-1945, Toulouse, Editions Privat.

Cioran E. M., 1988, Eseuri, București, Editura Cartea Românească.

Dasen P., Perregaux, C., Rey, M., 1999, Educație interculturală: experiențe, politici, strategii, Editura Polirom, Iaşi.

Fundoianu B., 1965, Poezii. Antologie și traduceri de Virgil Teodorescu, prefață de D. Petrescu, București, Editura pentru Literatură.

Fundoianu B., 1980, Imagini și cărți. Ediție de Vasile Teodorescu. Studiu introductiv de Mircea Martin. Traducere de Sorin Mărculescu, București, Editura Minerva.

Fundoianu B., 1998, Strigăt întru eternitate. Investigație documentară, alcătuire și îngrijire editorială: Geo Șerban, "Caiet cultural” (2), editat de Realitatea evreiască, Bucuresti.

Fondane B., 1933, Ulysse, Les Cahiers du Journal des Poètes, Bruxelles.

Fondane B., 1937, Titanic, Les Cahiers du Journal des Poètes, Bruxelles.

Fondane B., 1965, L’Exode. Super flumina Babylonis, La Société des Impriméries Maury.

Jutrin M., «L'irrésignation de Benjamin Fondane», Cahiers Benjamin Fondane, Jerusalem, 1998/ 2: 27.

Martin M., 1984, Introducere în opera lui B. Fundoianu, București, Editura Minerva. 